\title{
FINITUDE HUMANA E ENFERMAGEM: REFLEXÕES SOBRE O (DES)CUIDADO INTEGRAL E HUMANIZADO AO PACIENTE E SEUS FAMILIARES DURANTE O PROCESSO DE MORRER
}

\author{
HUMAN BEING FINITUDE AND NURSING: REFLECTIONS ON HUMANIZED AND \\ INTEGRAL CARE TO THE PATIENTS AND ITS FAMILIARS DURING THE DEATH PROCESS \\ FINITUD HUMANA Y ENFERMERÍA: REFLEXIONES SOBRE (DES)CUIDADO \\ GENERAL Y HUMANIZADO AL ENFERMO Y SUS FAMILIARES DURANTE \\ EL PROCESO DE MUERTE
}

\author{
Silvia C. Sprengel de Alencar* \\ Maria Ribeiro Lacerda** \\ Maria de Lourdes Centa***
}

* Mestranda do Programa de Pós-graduação em Enfermagem da Universidade Federal do Paraná.

** Doutora em Filosofia da Enfermagem. Professora Adjunta do Departamento de Enfermagem da Universidade Federal do Paraná. Coordenadora do Grupo de Estudos Multiprofissional em Saúde do Adulto (GEMSA)

*** Doutora em Filosofia da Enfermagem. Coordenadora do Grupo de Estudos Família, Saude e Desenvolvimento (GEFASED) da Universidade Federal do Paraná.

RESUMO. O artigo apresenta uma reflexão sobre o cuidado de enfermagem ao paciente e seus familiares diante da morte. Enfoca o cuidado integral e humanizado e visa à sensibilização da equipe de enfermagem e demais profissionais da equipe de saúde quanto à necessidade de um atendimento adequado ao ser humano, compreendido como um ente biopsicossocial, cultural e espiritual. Focaliza a morte como a única certeza que se tem desde o nascimento, permeada, porém, por diversos mecanismos de negação por parte do paciente e de seus familiares e até mesmo dos profissionais que o assistem, pois para o homem ocidental é corrente negar a sua finitude ao invés de aceitá-la. Evidencia que o cuidado de enfermagem prestado a pacientes e familiares diante do processo de morrer requer do enfermeiro eficiência técnico-científica, sensibilidade e interação, manifestando a arte da enfermagem como a empatia, intuição, percepção aguçada para atender às necessidades do paciente e de seus familiares. Deve, igualmente, respeitar a expressão dos sentimentos de dor, angústia, agressividade, abandono, perda, desespero, raiva, culpa, entre outros freqüentemente observados no transcorrer da vivência do processo de morrer. Diante destas constatações, este trabalho pretende contribuir para a sensibilização dos profissionais de saúde e, em especial, os da enfermagem e enfatizar a importância do cuidado integral e humanizado ao paciente, compartilhado com os familiares. Pretende ressaltar, também, a necessidade de abordagem do tema no decorrer da formação dos profissionais de saúde.

PALAVRAS-CHAVE: cuidados de enfermagem; família; morte.

ABSTRACT. This paper presents a reflection about nurse care to the patient and its relatives face the death. It focuses the integral and humanized care and aims to touch nursing team and others health professionals about the necessity to attend the human, as bio-psycho-social, cultural and spiritual being. Focalizes the death as the unique certainty that one have since was born, sometimes crossed by many denying mechanism, since for the occidental society is common to deny the finitude instead to accept it. It shows that the nurse care to the patients and relatives face to death process, demand technical efficiency, sensibility and interaction, manifesting the art of nursing as an empathy, intuition and perception to attend patient and its relative's needs. At same time must respect the expression of pain, aguish, abandon, loose, desperate, anger and others frequently observed on process of die. This paper wants to contribute to touch health workers, especially nurses and to emphasize the value of integral and humanized care. It also point out the necessity to discuss this subject during the graduation.

KEYWORDS: nurse care; family; death.

RESUMEN. Este articulo muestra una reflexión sobre el cuidado de enfermería dado a los enfermos y a su familia frente a la muerte. Enfoca el cuidado general y humanizado y busca sensibilizar el equipo de enfermería y demás profesionales del equipo de salud, frente a la necesidad de una atención adecuada al ser humano, viéndolo como un ser biopisicosocial, cultural y espiritual. Enfoca la muerte como el único hecho real que se tiene desde el nacimiento, rodeado sin embargo, por diversos mecanismos de negación por parte del enfermo y de sus familiares y hasta por los mismos profesionales que lo atienden, pues, para el hombre occidental es común negar su finitud en vez de aceptarla. Muestra que la atención de enfermería dado al enfermo y su familia frente al proceso de muerte, requiere del enfermero eficiencia técnico - científico, sensibilidad y acogimiento, mostrando el arte de la enfermería como el sentir, intuición, percepción aguda para atender las necesidades del enfermo y su familia. Debe también respetar la expresión de sentimientos de dolor, angustia, agresividad, abandono, perdida, desespero, rabia, culpa, entre otros, que a menudo son observados en el transcurso del proceso de muerte. Frente a estas constataciones este estudio pretende contribuir para la sensibilización de los profesionales de salud y en especial para los de enfermería y enfatizar la importancia del cuidado general y humanizado al enfermo y a su familia. Busca también resaltar la necesidad de un abordaje del tema durante la formación de los profesionales de salud.

PALABRAS-CLAVE: atención de enfermería; familia; muerte.

Recebido em: 23/11/2004

Aceito em: $\quad 30 / 04 / 2005$
Maria de Lourdes Centa

Rua Pará, 1235 - 80610-020 - Curitiba - PR

E-mail: mcenta@brturbo.com.br 


\section{INTRODUÇÃO}

A intensa velocidade da evolução dos avanços tecnológicos, a assistência centrada na cura em detrimento das medidas de prevenção à saúde, o atendimento institucionalizado do ambiente hospitalar, a diversidade dos serviços prestados pelos profissionais de saúde dentre outros fatores, têm contribuído para o inadequado atendimento das necessidades do ser humano, não só as de caráter biológico, mas também as psicológicas, afetivas, sociais e espirituais. Essas inovações, além de alterar significativamente o fazer dos profissionais de saúde, fizeram com que os espaços destinados para o morrer tenham se deslocado, na maioria das vezes, do ambiente domiciliar para o hospitalar.

Considerando o momento atual como de grandes transformações em todos os segmentos da sociedade, os profissionais de enfermagem precisam adotar mecanismos que permitam a discussão sobre a qualidade do cuidado prestado aos pacientes nos estabelecimentos de saúde, bem como à necessidade de legitimar este cuidado como foco principal do trabalho da equipe de enfermagem, o qual visa a valorização do ser humano em todas as etapas de seu ciclo de vida, desde o nascer até o morrer. O cuidado dispensado ao indivíduo, sadio ou doente, deve ser integral, evitando-se assim a fragmentação do atendimento de saúde prestado à população. Para isso, o cliente/paciente e seus familiares devem ser considerados como seres sociais e históricos, possuidores de crenças, valores, experiências de vida, medos, angústias e incertezas, expectativas e, por isso, devem ser respeitados, principalmente na vivência da situação de morte.

Os seres humanos, no hemisfério ocidental, demonstram dificuldade em falar sobre a morte e o morrer, um assunto bastante evitado no cotidiano, devido à imponderabilidade que se tem em falar, pensar e agir em relação a ela. Lembrar-se da morte remete à idéia de fim, de interrupção, de despedida, e de tantas outras questões para as quais não se encontram respostas e isto assombra o ser humano. Entretanto, ela não pode ser negada diante de uma situação concreta, como a internação de um paciente grave e/ou terminal, o que anuncia a possibilidade de morte iminente. Essa situação potencializa a sensação de impotência que os profissionais de saúde têm diante da morte e na (in)definição de como agir diante dos integrantes deste cenário, ou seja, paciente, familiares e demais profissionais. Grande parte desses profissionais, por não saberem abordar o assunto, ou por não terem vivenciado situações de perda/morte de pacientes sob seus cuidados no decorrer de suas formações acadêmicas, podem não se sentir aptos e nem saber como cuidar do paciente e seus familiares e, dessa forma estar impedindo que eles manifestem os seus temores, suas dúvidas e angústias próprias de sua condição.

Aos membros da família são apontadas dificuldades operacionais para que estejam ao lado de seu familiar doente, como se pouco participassem de sua vida. A família não é valorizada como peça fundamental do e para o cuidado, mas como quem deve esperar por escassas informações, por horários restritos para as visitas, e é considerada como alguém que "incomoda" quando faz perguntas sobre a recuperação de seu parente adoentado. Muitas vezes, inclusive, constata-se que os horários de visita destinados a um paciente grave e/ou terminal apenas é flexibilizado à família e pessoas de suas relações afetivas quando ele já está em seu estágio final, quando ele não os reconhece mais, não consegue falar, está inconsciente ou sedado. Estes fatos provocam questionamentos sobre esta ocorrência, pois este modo de agir permite a despedida apenas dos familiares e não a do paciente, pois quando as visitas são liberadas, na maioria das vezes, este já não está mais em condições físicas de comunicarse com sua família e expressar seus desejos.

Além disso, existe o mito da dor, responsável por um dos grandes medos do século atual, que é o sofrimento na hora da morte, pois permanece a crença de que o processo de morte é sempre acompanhado de dor e sofrimento insuportáveis ${ }^{1}$. Nestes casos, muitas vezes, os atores envolvidos neste processo, tendem a se afastar do paciente por 
acreditarem que não têm nada a fazer para ajudá-lo e, também, por medo de sofrer.

Baseada nesta realidade, propôs-se à reflexão sobre o cuidado dispensado ao paciente em estado grave ou terminal e a sua família, com o objetivo de contribuir para a sensibilização desta abordagem aos profissionais de saúde e, principalmente, os da enfermagem. $\mathrm{O}$ texto aponta como perspectivas $\mathrm{O}$ cuidado compartilhado entre profissionais de saúde e familiares, estimulando-os e permitindo o envolvimento pleno da família, valorizando-a como copartícipe deste processo. Enfatiza a importância da abordagem do tema no decorrer dos cursos de formação profissional das diversas áreas da saúde, com o intuito de despertar nos futuros profissionais a importância da interação com o paciente e familiares, não apenas nas questões de cunho técnico-científico, mas, em especial, nas de caráter subjetivo, como a vivência do processo do morrer.

\section{O PACIENTE, A FAMÍLIA E A SOCIEDADE DIANTE DO PROCESSO DE MORRER}

A morte vista como um acontecimento universal é a única certeza da condição humana e se traduz em um grande mistério acerca do qual se levanta inúmeros questionamentos, em especial, sobre a existência da vida após a morte. Ela não é mera falência física de um corpo biológico, pois institui um vazio interacional não só para a família e sua rede de relações, mas também para a sociedade em geral. Os sentimentos que afloram com a proximidade da morte são os mais diversos. Dentre os de caráter negativo temos: fracasso, impotência, silêncio, ódio, revolta, dor, culpa, irresolução, injustiça diante da perda, abandono de Deus; os de caráter positivo são: paz, celebração da própria vida, do valor da pessoa em vida, da terminalidade do tempo terreno, do cumprimento de uma etapa de vivência. Esses sentimentos levam o indivíduo a buscar o sentido da existência, da transcendência, no qual o ser humano se depara com a idéia da finitude.

A dificuldade e a necessidade intrínsecas de seres humanos em lidar com a morte, enquanto ocorrência universal e certa, expressam-se por meio da herança cultural e de sua história. Assim, "conhecimentos, imagens, sentimentos, representações simbólicas herdadas, produzidas e reproduzidas e integradas em nossa cultura engendram concepções humanas a respeito da vida e da morte" 2:2.

É natural o ser humano ter a percepção da morte com os outros e dos outros, nunca ligada à sua existência ou a de um dos seus familiares e/ou pessoas de suas relações afetivas, e isso se deve à idéia de valorização da imortalidade, da negação da morte, próprios da humanidade. Entretanto, a morte é um acontecimento inevitável que desperta a consciência da finitude, embora se procure mantê-la em estado de latência. Quando se depara com a morte em situações do cotidiano, como no caso de acidentes relatados em noticiários, a morte de um vizinho ou conhecido, nunca se imagina essa ocorrência em nossas vidas no presente, mas sempre em um futuro distante, quando se considerar as missões cumpridas, não só as de cunho profissional, mas também de caráter pessoal. Na prática, percebese que metas traçadas e alcançadas suscitam o planejamento de novas etapas, como se o ser humano pudesse contar com a imortalidade. Assim, de modo inconsciente e até concreto, o ser humano não conta com a possibilidade da morte para si mesmo e para aqueles de suas relações afetivas.

O tema morrer, apesar dos tabus da sociedade ocidental, tem sido objeto de interesse e de estudo de alguns profissionais da área da saúde, filosofia, sociologia e outras ciências. Elisabeth Kübler-Ross ${ }^{3}$, psiquiatra, escritora, notabilizada mundialmente por seus trabalhos junto a doentes terminais, iniciou seus estudos sobre a morte na década de 60 e, desde então, ensina que não se precisa, nem se deve, esperar que a morte bata à porta para se começar realmente a vivê-la, pois se a encararmos como companheira invisível, mas amigável, em nossa jornada de vida, lembrando-se de não esperar pelo amanhã para se realizar o que se deseja, então se pode aprender a viver a vida em vez de apenas passar por ela. 
Os cinco estágios da morte segundo KüblerRoss ${ }^{4}$, são: negação e isolamento, raiva e cólera, barganha ou regateio, depressão e aceitação ${ }^{3}$. A negação é a reação típica expressa pelo sujeito quando toma conhecimento de que sua doença é fatal. Esta é uma fase importante e necessária, pois ajuda a amenizar o impacto de saber que a morte é inevitável. Na fase de raiva e cólera o paciente elabora questionamentos como "por que eu" e afloram os sentimentos de raiva, de revolta, de inveja e de ressentimento. Neste processo, Deus é o alvo especial de sua cólera, porque Ele é considerado arbitrário, Aquele que impõe a sentença de morte. Entretanto, a cólera não só é permissível como inevitável. Após estas fases, o paciente aceita o fato da morte iminente, mas quer fazer acordos para poder viver um pouco mais de tempo, o que é denominado de regateio ou barganha. Neste período, a maioria das pessoas negocia com Deus, mesmo aquelas que nunca falaram com Ele. Elas prometem ser boas ou fazer algo em troca de mais uma semana, mês ou ano de vida. Quase sempre o paciente pretende um prolongamento de seus dias ou, então, que haja alívio de suas dores ou males físicos.

$\mathrm{Na}$ fase de depressão, o paciente lamenta perdas passadas, as coisas que não fez, os erros cometidos. Posteriormente, entra na fase de "luto preparatório", quando se apronta para a chegada da morte, tornando-se quieto e não querendo receber visitas, não desejando mais ver ninguém. Isto é sinal de que provavelmente o indivíduo resolveu seus negócios inacabados, podendo morrer pacificamente. Enquanto que na última fase, aceitação, a pessoa conscientiza-se e aceita que a sua hora está muito próxima. Neste estágio, o paciente que tenha tido tempo suficiente e auxílio para superar cada um dos estágios descritos, geralmente estará bastante fraco e cansado, sentirá necessidade de dormir com freqüência e a intervalos curtos, deseja que o deixem recluso, prefere um número limitado de visitas e não sente mais vontade de conversar e ouvir problemas do mundo exterior. A presença das pessoas de suas relações afetivas pode traduzir-se na garantia de que terá companhia até o fim, pois se trata realmente de uma trajetória única, inadiável, um momento de buscar a preparação para a hora da morte.

O conhecimento e a sensibilidade dos profissionais de enfermagem para apreender o significado de cada um desses estágios no processo de morrer fornecem subsídios para a compreensão das diferentes etapas com as quais os doentes e suas famílias se deparam frente à iminência da morte. Entretanto, eles não são absolutos, há que se ressaltar que nem sempre as pessoas atravessam todos os estágios, nesta exata seqüência. Contudo, se os profissionais de saúde tiverem o conhecimento sobre as fases do morrer e a sutileza em percebê-las nos momentos de aproximação com o paciente em fase terminal e sua família, isto pode tornar-se instrumento valioso no processo de cuidar de ambos. Perceber o que ocorre neste processo, leva-os a compreender o comportamento do paciente e das pessoas de suas relações afetivas no enfrentamento da morte iminente.

Dentre os fatores que influenciam o impacto e a repercussão da notícia ou a percepção da proximidade da morte, especialmente para os familiares, profissionais de saúde e sociedade, há a idade e as circunstâncias em que ela ocorre, a associação a estados mórbidos anteriores (doenças terminais, perda gradativa da autonomia quanto ao autocuidado, declínio no estado geral e sofrimento do doente), o vínculo estabelecido, dentre outros, sendo sempre muito forte o impacto da morte "prematura" e daquela resultante de causas violentas. É muito freqüente que familiares tentem proteger o paciente de sentimentos como a dor, o sofrimento e a angústia dos momentos derradeiros e queiram poupá-lo da vivência destes sentimentos, aceitando ou intercedendo para que ele seja sedado. Eles concordam com o tratamento suportivo mediante internação, pensando no bem-estar de seu parente adoentado e, também, pela insegurança/medo de mantê-lo em sua residência até a morte. Nestes casos, quando a morte sobrevém, comentam: "enfim, descansou", mostrando que apesar do imenso sentimento de perda que os assola naquele momento, e do vazio existencial que acompanha a 
morte, o amor existente naquela relação vai auxiliar a superar a sensação de privação. Com isso, acreditam que seu familiar ganhou o conforto de que tanto era merecedor, após a experiência dolorosa pela qual passou ao ser submetido a tratamentos opressivos, uso de materiais e equipamentos e internações prolongadas.

A idéia de morte pode ser associada ao rompimento súbito, inesperado e de modo irreversível dos vínculos existentes entre o ser humano e sua rede de relações. Neste processo, é incontestável a interferência do vínculo biológico e dos laços de afetividade na determinação dos sentimentos de perda, porém, qualquer que seja a sua origem, quando esse vínculo se rompe, ocorre dor e sofrimento, os quais, primeiramente, são de uma intensidade incomensurável, mas pode ser, também, um momento de aceitação, de tranqüilidade, de incremento da fé, de espiritualidade e de crenças, apesar da perda e do luto ${ }^{2}$.

Estudiosos referem que o choque é a primeira resposta à morte de uma pessoa importante ou querida, o qual será particularmente acentuado em casos de morte súbita e inesperada. As tentativas da pessoa que sofreu uma perda, para enfrentar essa fase de choque, irão variar de acordo com seu temperamento e a situação enfrentada, sendo que pode ir desde o completo entorpecimento e apatia, até a hiperatividade ${ }^{5}$.

Mesmo quando a morte já era esperada, sinalizada pela equipe de saúde para aqueles pacientes que estão vivenciando doenças insidiosas, progressivas e terminais, o momento da morte decreta um fim. Ela representa um instante de desequilíbrio e de desconstrução, no qual os familiares perdem o ponto de referência, que era marcado pelos horários estabelecidos para o cuidado junto ao doente, o rodízio realizado entre os familiares para garantir a permanência 24 horas ao seu lado, pois há muito tempo eles já haviam modificado o cotidiano de suas vidas, devido o processo de adoecimento vivenciado.

Algumas famílias, ao se depararem com o impacto da notícia da morte de seu familiar, procuram encontrar um sentido para esta ocorrência e forças para continuar a viver. Questionamentos intermináveis, sentimentos de culpa, a impressão de que algo poderia ter sido feito para evitar a morte, inquietações, fazem com que os familiares busquem na fé e na crença a força para continuar vivendo e à busca de novos valores. Há, entretanto, famílias que manifestam revolta contra Deus, sentem-se abandonadas por Ele e não conseguem aceitar a perda naquele contexto.

A própria sociedade utiliza mecanismos que tentam encarar a mortalidade como parte de nossa existência, apoiando-se em eufemismos para enfrentar as questões da morte, como: "Enfim, descansou" ... "passou desta para melhor" ... "ele se foi" ... "agora está em paz" ... "nos abandonou" ... "dorme para sempre" ... "agora não sofre mais" ... "está com Deus"; isso ocorre como uma tentativa para consolar aqueles que estão sofrendo com a perda ${ }^{6}$.

A morte é um tema evitado, ignorado e negado por nossa sociedade, que cultua a juventude e que se orienta para o progresso. A morte, na verdade, é tão parte da existência humana, do seu crescimento e desenvolvimento quanto o nascimento. (...) estabelece um limite em nosso tempo de vida, e nos impele a fazer algo produtivo nesse espaço de tempo, enquanto dispusermos dele ${ }^{7: 13}$.

O problema central da existência humana é a finitude e, acompanhar a vivência de momentos derradeiros dos outros nos remete à lembrança de nossa própria finitude, ocasionando ansiedade existencial e desconforto espiritual nos profissionais de saúde ${ }^{8}$.

\section{A PERSPECTIVA DE UM CUIDADO INTEGRAL, HUMANIZADO E COMPARTILHADO ENTRE O PACIENTE, A FAMÍLIA E PROFICIONAIS DE SAÚDE DIANTE DO PROCESSO DE MORRER}

"Ter cuidado com alguém ou alguma coisa é um sentimento inerente ao ser humano, ou seja, é natural da espécie humana, faz parte da luta pela sobrevivência e percorre toda humanidade" 9:29. A enfermeira realmente cuidadora encara o cuidado como ação humana, superando o saber biológico, 
técnico e a aplicação impessoal do seu saber. Ela considera o paciente e seus familiares em seu ciclo de vida, suas experiências, sua integralidade e múltiplos aspectos e dimensões como seres humanos ${ }^{9}$.

O cuidar é o objetivo principal dos profissionais de enfermagem, os quais, para cuidar com eficiência e resolutividade, devem envolver na ação do cuidado, não apenas os seus clientes/pacientes, mas também a família e significantes ${ }^{10}$.

O cuidado de enfermagem, portanto, deve incluir a família em todos os momentos, quantos forem possíveis, favorecendo a sua participação no cuidado ao paciente, já que ela está vivenciando instantes de dificuldades com seu adoecimento. Neste processo, a família vivencia medos e incertezas relacionadas ao diagnóstico e prognóstico da patologia, bem como sobre o estado do paciente frente à doença e a possibilidade de morte. Deixá-la alheia à situação vivida por seu familiar gera angústia, resultando em incertezas, ansiedades, medos e crises. Mesmo que a família tenha dificuldades em aceitar ocorrências negativas em relação ao estado de seu familiar, com a possibilidade de morte ela tem o direito de saber o que está acontecendo, agir, reagir e tomar decisões.

Neste processo de vida/morte iminente, a família faz uso dos mecanismos de negação, negociação e adaptação à situação vivida pelo seu familiar doente e deve ser informada sobre o seu real estado de saúde para que, então, possa expressar e minimizar os sentimentos, preparar-se para acolher os fatos e procedimentos, a enfrentar ocorrências negativas, inclusive a morte.

Assim, o cuidado compartilhado entre os profissionais de saúde e os cuidadores/familiares deve ser estimulado e valorizado, especialmente naqueles casos em que o processo de adoecimento se estende por vários meses e até anos, nos quais a tranqüilidade conferida ao paciente, pela presença efetiva do familiar a seu lado, tem valor relevante e não deve ser menosprezada. Inúmeras vezes, esbarra-se nos impedimentos institucionais, que não permitem a presença do acompanhante em tempo integral, ou quando ele tem liberação para permanecer na instituição, o é por ser considerado como mão-deobra adicional.

A presença da família como parte essencial do cuidado a pacientes terminais é inquestionável, entretanto, muitas são as dificuldades apresentadas para aqueles que se dispõem a incorporá-la neste processo. O cuidado integral e humano prestado pelas e às famílias nem sempre é compreendido e acessado por muitos dos integrantes da equipe de saúde em seu cotidiano. Os enfermeiros que estão sensibilizados para cuidar da família são unânimes em referir os obstáculos institucionais e os malabarismos que necessitam fazer para não ferir as normas estabelecidas e ao mesmo tempo acolher e inserir as famílias em seu processo de trabalho ${ }^{11}$.

Para que o cuidado se desenvolva de forma integral e humanitária, o enfermeiro deve atender às necessidades de seus clientes/pacientes e de seus familiares, interagindo com eles, resolvendo problemas, apontando soluções, propiciando melhora da sua condição de saúde, ou proporcionando uma morte digna e com serenidade ${ }^{9}$.

Desse modo, é importante compreender a morte como processo, e não apenas como um resultado final, um fim, pois se o paciente terminal for considerado como um ser social e histórico, com crenças e valores próprios, que está inserido em um contexto familiar e social, cuidá-lo, nestes momentos críticos, é buscar entendê-lo, ouvi-lo, respeitá-lo. Nesse processo devem ser consideradas suas manifestações verbais e não-verbais, pois elas traduzem, muitas vezes, desagrado, raiva, medo, ansiedade, expectativas, frustrações, dentre outros sentimentos. É importante, também, garantir a presença dos familiares e significantes, conforme 0 desejo do paciente, procurando inseri-los no processo de cuidar e ser cuidado, de modo compartilhado com a equipe de saúde.

É por intermédio das ações de cuidar que os profissionais de enfermagem demonstram o compromisso com a vida. Esses profissionais lutam para manter o fluxo da vida, mesmo acreditando que a morte pode ocorrer em uma dimensão que 
transcende, na maioria das vezes, a sua compreensão. Assim, falar de morte e de vida é falar de muitas dúvidas que afligem o espírito, aguçam o pensamento e aumentam as nossas angústias e reflexões. É conviver com os opostos, como a força e a fraqueza, o abstrato e o concreto, o objetivo e o subjetivo, o racional e o irracional, o sensitivo, o corporal e o espiritual ${ }^{12}$.

Cuidar, neste momento crucial de vida/morte, requer dos profissionais de saúde, sensibilidade, envolvimento, empatia, olhar atento, percepção aguçada, interação, conhecimento e crença. Somente agindo dessa forma, pode-se cuidar com eficiência e resolutividade do paciente e seus familiares nesta fase de enfrentamento. Neste processo, é necessário que os profissionais compreendam, reflitam e se questionem sobre o rito de passagem da vida para morte, para poder cuidar com qualidade, pois a morte é uma experiência existencial na vida do homem.

\section{O ENSINO E A ABORDAGEM DO PROCESSO DE MORRER NO DECORRER DA FORMAÇÃO DOS PROFISSIONAIS DE SAÚDE}

Atualmente, a maioria das pessoas não assiste seus parentes morrerem, pois a morte geralmente ocorre em ambiente hospitalar, ficando a família afastada do cuidado das pessoas de suas relações afetivas, no decorrer do processo de morrer, obedecendo a normas e regras da instituição. A exclusão da família, neste processo, é justificada pela sua possível interferência, no trabalho da equipe de profissionais, os quais procuram tornar invisível a presença da morte. Com isso, eles afastam, de suas ações, a presença dos familiares com suas lamentações, choros e questionamentos, cuidando apenas do indivíduo doente. Talvez, os profissionais de saúde não considerem o paciente moribundo e seus familiares como prioridade de atendimento, pois no decorrer de suas formações acadêmicas é enfatizada a valorização da vida, pois a morte os assombra e representa um fracasso assistencial. Provavelmente, os profissionais de saúde que estejam diante do paciente e familiares no decorrer do processo de morrer, não tenham conhecimento suficiente ou não compreendam os estágios pelos quais passam paciente e familiares ao saber ou pressentir a morte iminente ${ }^{13}$.

A ocorrência da morte em ambientes hospitalares torna difícil a sua comunicação, por parte da equipe de saúde, para os familiares. Essa dificuldade é expressa pela supressão do uso da palavra "morte", a qual é substituída por outros termos como "parada cardíaca ou respiratória", dentre outros. Esta questão parece estar relacionada ao fato de que a morte em ambiente hospitalar é identificada como fracasso da instituição e da equipe profissional ${ }^{14}$.

Para os profissionais que atuam junto a pacientes terminais, a morte, além de ser uma preocupação pessoal, faz parte do seu cotidiano, pois eles são submetidos diariamente a situações de tensão diante de pacientes graves/terminais, os quais, às vezes, morrem em suas mãos. Muitos deles relatam sua impotência e frustração perante a imprevisibilidade da trajetória da morte. É como se nesses momentos estivessem diante da fragilidade de sua existência, recordando-se de sua própria finitude e da possibilidade de viver a mesma situação de seus pacientes e de suas famílias. A negação, então, pode surgir como uma forma de defesa, para não entrar em contato com a fragilidade desta ocorrência e como reflexão de sua própria finitude. Por outro lado, os avanços tecnológicos da medicina e da farmacologia podem despertar, nesses profissionais, o desejo de ser o herói, ou seja, o desafiador da morte ${ }^{13}$.

Os profissionais de enfermagem relatam que, muitas vezes, não estão preparados para presenciar a morte, pois ela desperta sentimentos de fracasso e tristeza, e eles vivenciam em seu cotidiano o desafio de preservar a vida ${ }^{9}$.

Embora de modo inconsciente, a negativa da morte é a principal ação defendida pelas instituições e pelas suas equipes de saúde. O hospital, por meio de sua equipe de profissionais, tende a estimular 0 paciente a manter-se na fase negativa, porque isso os protege, evitando que se envolvam e que tenham 
de encarar seus próprios sentimentos e frustrações, ou de comunicar-se entre si expondo limitações, e com a família, relatando a situação. Assim, quando alguém morre em um hospital, o corpo é rapidamente retirado do local para não chocar as pessoas, pois neste ambiente os pacientes não morrem: expiram ${ }^{3}$.

Os pacientes terminais incomodam os profissionais de saúde, por suas atitudes de revolta, de dor, por suas exigências ou porque eles dão as costas à vida, desistindo de viver ${ }^{14}$. Na verdade, a formação dos profissionais de saúde enfatiza a cura, o retorno ao ambiente domiciliar, o controle das doenças crônicas, quando, na verdade, são negligenciados conteúdos como o processo de morrer, dentre outros, pois estes frustram os profissionais que estão preparados para os êxitos e não para as perdas, que podem soar como insucesso ${ }^{15}$.

Para os enfermeiros, cuidar de pacientes terminais, mantê-los limpos, confortáveis e sem dor é uma das tarefas mais difíceis, pois em sua formação, em geral, são enfatizados os aspectos técnicos da profissão em detrimento das questões ligadas à emoção, principalmente as causadas pela morte. O enfermeiro é quem está próximo do paciente nos momentos mais difíceis de seu viver; é quem o paciente procura para conversar sobre os seus temores, anseios, expectativas, sonhos ou medos, inclusive sobre a morte; é, também, quem está ao lado da família, aparando-a e ajudando-a a lidar com os seus sentimentos, dúvidas, angústias, temores, pois quando o paciente falece é o enfermeiro quem toma as primeiras providências ${ }^{18}$.

As questões mencionadas traduzem a importância do tema ser incluído e abordado nos currículos de enfermagem e demais profissões da área da saúde desde o início do curso, de forma a instrumentalizar os profissionais a lidar com esses aspectos subjetivos e, por vezes, dolorosos, mas que são inerentes à profissão .

As instituições de ensino dão ao tema morte, uma visão errônea, ou seja,

grande parte de nossas faculdades, devido a uma distorção curricular, está unicamente preocupada em qualificar pessoas aptas para curar, tratar e prolongar a vida, porém, bem pouco aptas para assistir psicológica e humanamente pacientes que não vão se recuperar. Em conseqüência disso, os médicos e os enfermeiros se encontram tão despreparados quanto a maior parte dos leigos e, dessa forma, transmitem inevitavelmente aos moribundos e aos seus familiares a impressão de abandoná-los à dor e à solidão 17:40-1.

Em minha prática profissional, percebo que lidar com o paciente em fase terminal, o agonizante ou em estado grave, requer dos profissionais da área da saúde um preparo que não é devidamente desenvolvido pelas escolas, ou quando isso ocorre, este assunto é abordado rapidamente e de forma superficial, enfocando a parte prática, sem dar a devida importância ao subjetivo, ao rito e ao mito que envolve este processo. Isto faz com que os profissionais de saúde sejam colocados no mercado de trabalho pouco preparados e com escasso conhecimento para enfrentar esta ocorrência. Assim sendo, quando estes profissionais têm de enfrentar a morte em seu cotidiano de trabalho, muitas vezes fogem, demonstrando falta de envolvimento e frieza, permitindo que as famílias os julguem de forma negativa pelo inadequado cuidado e apoio recebidos.

Àqueles que acompanharam os momentos derradeiros de um paciente e souberam utilizar estes instantes para buscar o conforto físico/psicológico/ espiritual, ambiente adequado, a proximidade dos familiares, apertaram-Ihe as mãos, proferiram frases curtas e nítidas, orientaram os familiares quanto a evitar comentários desagradáveis e excessivos choros próximos ao paciente, puderam de fato apoiar os familiares e demonstrar a sua presença efetiva como pessoa e como profissional. Enfim, àqueles que deram oportunidade para que os familiares se manifestassem e expressassem seus sentimentos, suas inquietações e suas revoltas (muito semelhantes àquelas expressas pelo paciente durante as fases da morte), assim como as do paciente, demonstrarão a tranqüilidade em dizer que estiveram de fato ao 
lado do paciente e familiares até o fim e os cuidaram de forma humana e integral.

Vivenciar esta realidade nas instituições de saúde não é tarefa fácil, entretanto deve-se atuar de forma consciente, ética e responsável, contribuindo para a transformação de comportamentos e posturas em relação ao paciente terminal e às suas famílias. Nossas ações como enfermeiros devem envolver os demais elementos integrantes do processo, buscando sensibilizá-los para cuidar de forma integral e humanizada, tanto o paciente em fase terminal/grave como suas famílias e rede de relações.

\section{CONSIDERAÇÕES FINAIS}

A morte é considerada a última etapa da vida, porém raramente se pensa nela, negando a certeza de que algum dia teremos de enfrentá-la. Isto talvez ocorra pelo medo do desconhecido, pela sensação de perda, de separação daqueles que se ama. Entretanto, há necessidade de se encarar a morte como uma fase do nosso processo existencial, o qual deve ser vivido da forma mais harmônica e digna possível, experienciando todos os seus estágios.

O enfermeiro e os demais profissionais de saúde devem conhecer e compreender os estágios pelos quais passam os pacientes em fase terminal/graves e seus familiares para desenvolver suas ações de forma integral, particularizada, humanizada e compartilhada. Para que isso ocorra com qualidade e resolutividade, deve-se ter uma postura de compromisso com a ética, com o respeito à individualidade humana, com o saber ouvir e calar quando necessário. É importante ainda, ter a percepção e compreensão dos momentos difíceis vividos e manifestos pela comunicação verbal e nãoverbal, procurando atuar em equipe, atendendo o paciente e seus familiares com discrição e competência, fazendo-os reconhecer nas ações de enfermagem o suporte e apoio de que necessitam nestas horas difíceis. Enfim, fazer a diferença no cuidar do indivíduo e sua família.

Assim, os profissionais de saúde devem constantemente buscar um preparo específico, pois esta situação exige ações que envolvem outros conhecimentos, como os da esfera social, afetiva e humana, além dos técnico-científicos. Este processo de cuidar de pacientes em fase terminal/graves e seus familiares requer dos profissionais maior envolvimento biopsicossocial, cultural e espiritual, pois este rito de passagem está envolto em mitos, muitas vezes, expressos subjetivamente. Se se considerar que trabalhar com a morte é lidar com o inesperado, com o impacto, com o rompimento de vínculos estabelecidos (profissionais, pessoais e familiares), e reconhecer que ela é um acontecimento inexorável em todas as existências, porém cercado de um enorme mistério, ocorrerá a conscientização da importância da ação dos profissionais de saúde nesta ocorrência da vida.

Para que os profissionais que atuam na enfermagem e demais áreas da saúde possam desenvolver suas ações com competência, eficácia e sensibilidade, devem ser preparados para enfrentar esta situação. Portanto, as escolas devem ter o compromisso de sua formação, ensinar-lhes a lidar com pacientes terminais e seus familiares, não só enfocando o conhecimento teórico-prático visível, mas também o subjetivo vivido. Este último, muitas vezes fornece informações importantes para melhor se enfrentar o encontro e a vivência da finitude e se proporcionar cuidado de qualidade aos envolvidos, contemplando o atendimento de inúmeras necessidades manifestas verbalmente ou não, mas presentes nessas situações de transição vida-morte.

Portanto, atuando como profissionais de saúde junto a pacientes e familiares na vivência do processo de morrer, deve-se ter a disponibilidade e sensibilidade para perceber suas vulnerabilidades, acolhendo-os e atendendo-os de modo particularizado. Transpor as barreiras impostas pela cultura ocidental, que nega a morte em inúmeras situações, e pelas dificuldades estabelecidas pelas instituições de saúde são dois grandes desafios; encorajar os estudantes a enfrentar as situações de morte iminente ao invés de poupálos; estimular a comunicação aberta e franca entre paciente/familiares/profissionais de saúde, permitindo 
e facilitando o cuidado compartilhado entre os profissionais de saúde e familiares são algumas das perspectivas que podem contribuir para que cada paciente terminal, possuidor de uma trajetória pessoal de vida e de adoecimento, incorporada numa situação familiar e cultural, única, sinta-se, de fato, acolhido e cuidado no processo de enfrentamento da morte.

\section{REFERÊNCIAS}

1 Kovács MJ. Pensando a morte e a formação de profissionais de saúde. In: Cassorla RMS. Da morte: estudos brasileiros. Campinas: Papirus; 1991.

2 Martins G. Laços atados: a morte do jovem no discurso materno. Curitiba: Moinho do Verbo; 2001.

3 Kübler-Ross E. Morte: estágio final da evolução. Rio de Janeiro: Nova Era; 1996.

4 Sobre a morte e o morrer. São Paulo: Martins Fontes; 2002.

5 Pincus L. A família e a morte: como enfrentar o luto. Rio de Janeiro: Paz e Terra; 1989.

6 Fraiman A. Coisas da idade. São Paulo: Editora Gente; 1995.

7 Braga J L, Braga L D Prólogo. In: Kübler-Ross E. Morte: estágio final da evolução. Rio de Janeiro: Nova Era; 1996.

8 Radünz V. Uma filosofia para enfermeiros: o cuidar de si, a convivência com a finitude e a evitabilidade do burnout. Florianópolis. Série Teses em enfermagem; 2001.
9 Costenaro RGS, Lacerda MR. Quem cuida de quem cuida, quem cuida do cuidador. Santa Maria: Centro Universitário Franciscano; 2002.

10 Zamberlan C, Costenaro RGS. O fortalecimento do relacionamento interpessoal: um fator determinante da prática do cuidado em UTI. In: Costenaro RGS, organizadora. Cuidando em enfermagem: pesquisas e reflexões. Santa Maria: Centro Universitário Franciscano; 2001.

11 Angelo M. Com a família em tempos difíceis: uma perspectiva de enfermagem. [tese]. São Paulo (SP): Escola de Enfermagem da Universidade de São Paulo; 1997.

12 Lacerda M, Costenaro RGS. O cuidado como manifestação do ser e fazer da enfermagem. Santa Maria: Vidya 1999; 1(1).

13 Figueiredo NMA, et al. A dama de branco transcendendo para a vida/morte através do toque. In: Meyer DE et al, organizadoras. Marcas da diversidade: saberes e fazeres da enfermagem contemporânea. Porto Alegre: Artes Médicas; 1998.

14 Kovács MJ. Pensando a morte e a formação de profissionais de saúde. In: Cassorla RMS (coordenador). Da morte: estudos brasileiros. Campinas: Papirus; 1991.

15 Klafke TE. O médico lidando com a morte: aspectos da relação médico-paciente terminal em cancerologia. In: Cassorla R M S (Coordenador) Da morte: estudos brasileiros. Campinas: Papirus; 1991.

16 Kovács MJ. Morte e desenvolvimento humano. São Paulo: Casa do Psicólogo; 1992.

17 Maranhão JLS. O que é morte. São Paulo: Brasiliense; 1996. 